Royal Cancer Hospital, Fulham Road, London, S.W.3, from whom further particulars of the Group and its membership can be obtained.

\section{The Anthropologist: New Indian Journal}

Is the India of to-day many diverse populations are being brought into contact with each other. The network of communications extends to the remotest areas, and tribal cultures at all levels are meeting Western civilization at an increasing rate. This has led to an equally increasing activity in the field of anthropology both by non-Indians and Indians. A welcome is to be extended, therefore, to The Anthro pologist, a biannual journal edited by the Department of Anthropology of the University of Delhi (Rs. 6 a year or Rs. 3.8 a copy). Although the managing director is Dr. P. C. Biswas of Delhi, the editorial board is not restricted to his Department. Among others, it includes B. S. Guha, director of the Department of Anthropology of the Indian Museum in Calcutta, and the first article in the first number is by Ernst C. Büchi of that Department. Incidentally, this is a most valuable contribution to our knowledge of the blood-group secretor factors in India, a demonstration that the secretor status will become important in recognizing the varied composition of mixed Indian communities. The same number of the journal contains a study of juvenile delinquents by P. C. Biswas, anthropometric studies of the Bhotias by S. C. Tiwari, 'a cultural essay on the Naiks by J. D. Mehra and papers on fingerprint patterns and blood groups. The second number has now appeared and continues along these varied lines, with contributions by Büchi, notably one on the question of sickling in Indian aboriginals, by G. R. Gayre from Saugar, S. C. Dube from Hyderabad and by the Delhi group. We can look forward to a stimulating contribution from India in this field.

\section{Risks to Wild Life of Agricultural Chemicals}

THERE has naturally been some concern in Great Britain lest the widespread use of chemicals to destroy pests and weeds should be a source of undesirable or even dangerous secondary effects. The risks run by operatives handling such substances and the possibility of harm from eating food exposed to them have already been discussed in two earlier reports ("Toxic Chemicals in Agriculture", 1951 ; and "Toxic Chemicals in Agriculture : Residues in Food", 1953). A third report, "Toxic Chemicals in Agriculture: Risks to Wild Life", has now been published (pp. 31 . London: H.M.S.O.; $1 s .6 d$. net). According to evidence collected from a large number of organizations and individuals and some field-experiments carried out to gain information of a more precise nature, it seems that casualties to mammals and birds (including game) due to sprays are probably small. The substances most likely to be harmful are organophosphorus insecticides applied to brassicas in late summer, arsenical compounds used for potato haulm destruction, dinitro weed-killers applied in spring, and DDT insecticides applied to orchards, carrots and peas. Details of some actual fatalities that have occurred are given, and precautionary methods suggested. Danger to insects is probably much greater but more difficult to evaluate. Effects of sprays on honey bees have received special attention in view of the increasing losses reported, and closer cooperation is urged between beekeepers, farmers and spraying contractors. The inquiry has brought to light the need for research and investigation, and among lines of work suggested are the effect on birds of killing large numbers of insects and the extent to which seed production of sprayed crops is reduced by the death of pollinating insects.

\section{Rubber Research Institute of Malaya}

IN the current annual report of the Rubber Research Institute of Malaya for 1952 (Kuala Isumpur, 1954), an account is given of the fourth year of operation of the five-year programme of expansion of the organization and work of the Institute. The present report contains an introduction by the Director and accounts of the work of the several Divisions - Soils, Botany, Pathology and Chemistryeach subdivided into research and advisory sections. An account is also given of the Smallholders' Advisory Service. Work on the rubber tree includes breeding and selection, a study of tapping systems, various soil investigations, cultivation and manuring, and the control of diseases and pests. Work on the product begins from the moment of tapping and continues through all the subsequent processes, that is, it includes the collection and treatment of latex and its processing through to the final product for export. These studies are in the hands of the Chemical Division. Fuller accounts of the experimental work of the Institute are to be found in its Journal, the annual reports being intended to fulfil a more general purpose.

\section{Observatory Department, Mauritius : Report for} 1953

THE report of the Observatory Department of the Colony of Mauritius for the year 1953 (pp. 16. Port louis: Government Printer, 1954) describes the general functions of the Department under various headings, including provisions of meteorological services for the government departments, local authorities, the press and general public, agricultural and commercial interests, the Armed Services, the merchant navy and civil aviation; warnings of tropical cyclones; research; and other activities. Besides the Royal Alfred Observatory, the Department also maintains a number of stations at Pamplemousses, Vacoas, Plaisance Airfield, Agalega, St. Brandon and other places. In addition to the director, E. G. Davy, there are an assistant director and thirty-four others on the staff. Descriptions are given of the inspections and visits, buildings, meteorological instruments, magnetic instruments and other equipment, etc. It is interesting to notice that towards the end of 1953 research work was in progress on the influence of rainfall on the rates of growth and maturity of the sugar cane. As the Colony's income depends almost entirely on agricultural products, the Department devotes most attention to agricultural meteorology. During 1953, progress in reorganizing and extending the Department was more substantial than had been possible to report in previous post-war years. This is chiefly attributed to the provision of adequate accornmodation at the Vacoas headquarters, the fllling of one of the posts of assistant meteorologist, and the increasing experience of observers appointed in 1949 and 1950. Further funds for building having becomo available and hopes of filling all staff vacancies in 1954 being entertained, the report ends on the optimistic note that "the prospects at the end of 1953 were brighter than they have been for a number of years". 